\title{
Effect of tarragon (Artemisia dracunculus L.) extract on spatial memory in rats exposed to chronic immobilization stress
}

\author{
Hajar Khosravi $^{1}(\mathbb{D})$, Mehdi Rahnema $^{2}(\mathbb{D})$, Masoumeh Asle-Rousta ${ }^{1}$ \\ ${ }^{1}$ Department of Physiology, Zanjan Branch, Islamic Azad University, Zanjan, Iran \\ ${ }^{2}$ Corresponding Author; Department of Physiology, Zanjan Branch, Islamic Azad University, Zanjan, Iran \\ Tel: +982433420030Ｅmail:meh_rahnema@yahoo.com
}



\begin{abstract}
Background and Aim: Tarragon (Artemisia dracunculus L.) has antioxidant, anti-inflammatory and analgesic effects. The objective of this study was to investigate the effect of Tarragon alcoholic extract on spatial learning and memory deficits, induced by chronic immobilization stress in male rats.

Materials and Methods: In this experimental study, 60 male Wistar rats were divided into 6 groups (each group of 10 rats): Control(without treatment), under stress, receiving $100 \mathrm{mg} / \mathrm{kg}$ Tarragon extract, receiving $500 \mathrm{mg} / \mathrm{kg}$ Tarragon extract, stress receiving and $100 \mathrm{mg} / \mathrm{kg}$ Tarragon extract simultaneously, and finally Stress receiving group and $500 \mathrm{mg} / \mathrm{kg}$ tarragon extract simultaneously. The rats in under stress group, 6 hours every day for 21 consecutive days they encountered with immobilized stress. Groups receiving Tarragon extract, during this period, the doses of $100 \mathrm{mg} / \mathrm{kg} . \mathrm{bw}$ and $500 \mathrm{mg} / \mathrm{kg} . \mathrm{bw}$ were extracted by gavage, and two groups receiving the extract and stress simultaneously, in addition to receiving Tarragon extract at the same doses they also faced stress. Spatial learning and memory of animals were evaluated by using the Morris Water Maze test.

Results Immobilized stress impaired learning and memory in animals. Delay time (seconds) and distance (cm) moved to reach the hidden platform was significantly increased in the stress group compared to the control group $(\mathrm{P}<0.01$ and $\mathrm{P}<0.05$, respectively).

Also in probe test, total elapsed time $(\mathrm{s})$ and distance $(\mathrm{cm})$ in target quadrant decreased significantly in stress group compare with control group $(\mathrm{p}<0.001$ and $\mathrm{p}<0.05$ respectively). Receiving both doses of Tarragon extract improved spatial learning and memory in under stressed rats.
\end{abstract}

Conclusion: The results of this study indicate that Tarragon extract prevent memory impairment and may be useful in preventing and treating of neuro-degenerative diseases due to stress.

Key Words: Tarragon (Artemisia dracunculus); Memory; Immobilization Stress 


\title{
بررسى اثر عصاره ترخون (Artemisia dracunculus L) \\ بر حافظه فضايى موشهاى صحرايى مواجهشده





زمينه و هدف: ترخون (Artemisia dracunculus L.) اثرات آنتىاكسيدانى، ضدّ التهابى و ضدّ درد دارد. هدف از مطالعه حاضر،













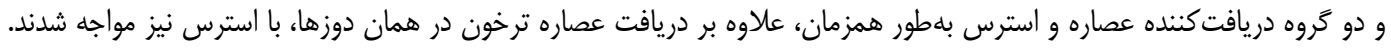



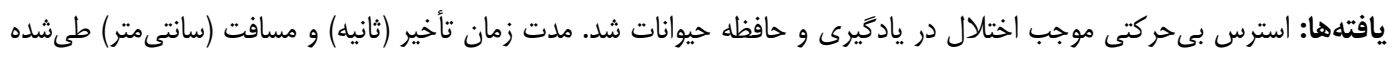



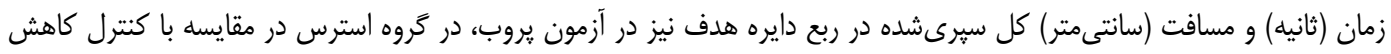

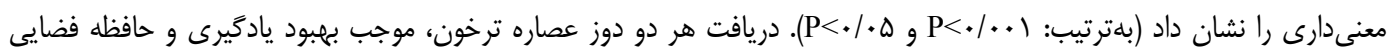
در موشهاى تحت استرس شد.




وازههاى كليدى: ترخون (Artemisia dracunculus)؛ حافظه؛ استرس بىحر كتى


دريافت:

' كروه فيزيولوزى، واحد زنجان، دانشكاه آزاد اسلامى، زنجان، ايران




ايميل:meh_rahnema@yahoo.com




تركيبات موجود در مواد غذايى هستند، اثرات سوء آنها نيز

حداقل است (ه).

زياهى أن (Artemisia dracunculus

L) ترخون خانواده Asteraceae است. مهمترين مواد تشكيلدهنده ترخون عبارتند از: فلاونوئيدها، كومارينها، تركيبات فنلى،



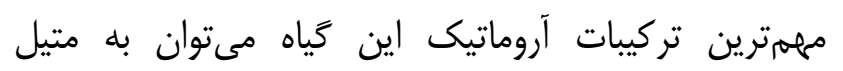
اوخنول، كارواكرول و تيمول اشاره كرد. بسيارى از اروماتيك مواد

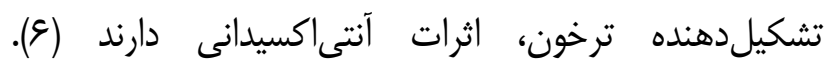

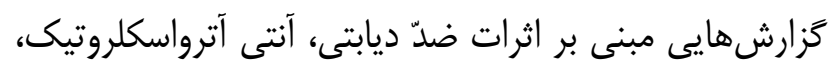


ترخون وجود دارد (q-q). بر اساس اين اثرات محافظتى و با توجه به آن آن كه آنه


سودمند مىباشند (•(1)، فرض شد كه ترخون بر حافظه تأثير




صحرايى نر تحت استرس مزمن بى هر كتى، مورد مطالعه قرار

كرفت.

\section{روش تحقيق}

در اين مطالعه تجربى، •ع سر رت نر از نزاد ويستار به

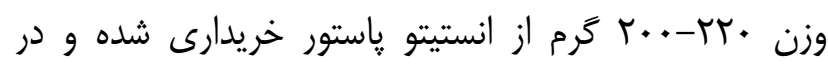

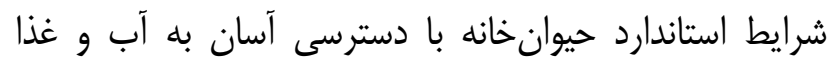

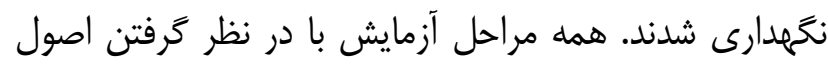

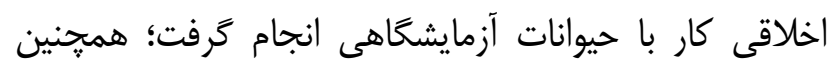

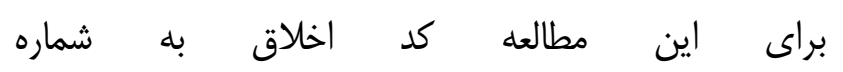
IR.IAU.Z.REC.1396.18 از كميته اخلاق دانشعاه آزاد اسلامى واحد زنجان دريافت گرديد.







استرسها موجب بروز اختلال در هومئوستازى


تنشزا با تأثير بر هييوتالاموس و مراكز بالاتر از آن، محور




استرسزاى مختلف، با افزايش توليد راديكالهاى آزاد نظير

















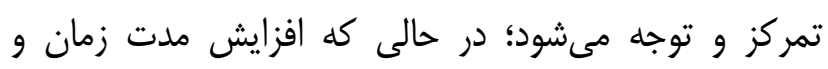








راديكالهاى آزاد، التهاب عصبى، مهار نوروزنز، عقبنشيت نحينى



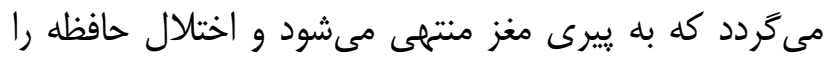

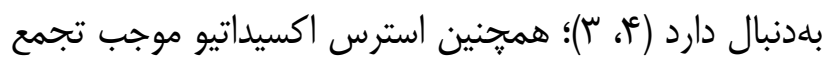

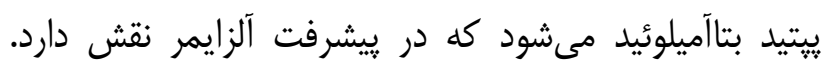
يكى رابطه دوطرفه بين دو عامل مذكور وجود دارد (سا).









${ }_{2}^{1}$ Reactive oxygen species

${ }^{2}$ Long term potentiation 


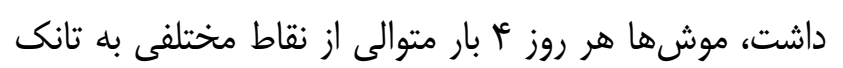

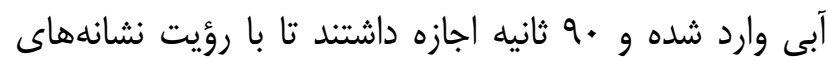

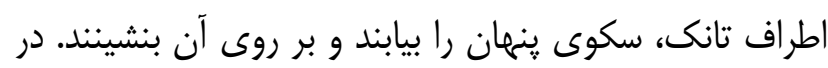

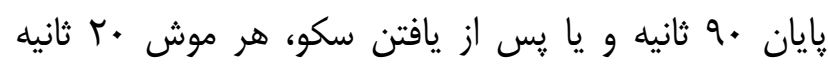

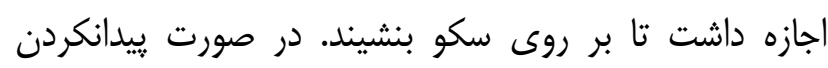

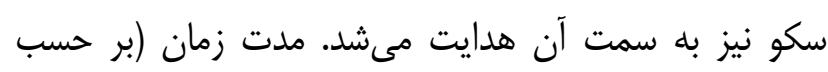
ثانيه) و مسافت سيرىشده (بر حسب سانتىمتر) براى رسيدن به سكوى ينهان توسط دوربين به نرمافزار

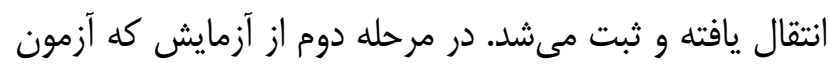

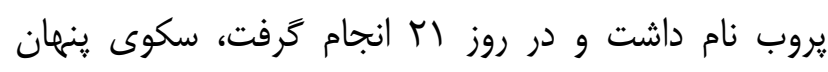

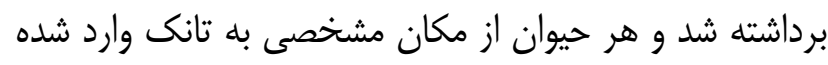


مسافت شنا شده (سانتى متر) در ربع دايره هدف (ربع دايرهاى دانى







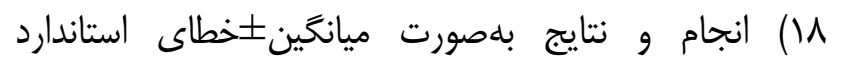
ميانخين (SEM) ارائه شد. براى تجزيه و تحليل دادهها از

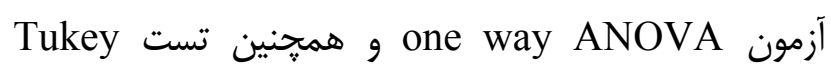
استفاده شد. مقايسه يادگيرى بين هر گروه


سطح معنىدارى نتايج در نظر كرفته شد.

\section{يافته ها}

نتايج آمارى فاز اكتساب نشان داد كه يادگيرى در همه

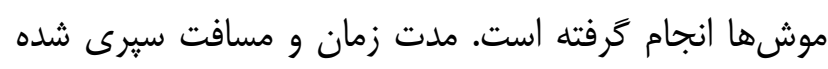

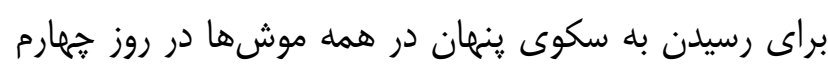

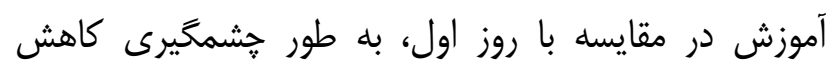

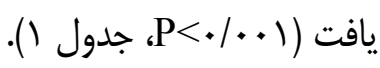

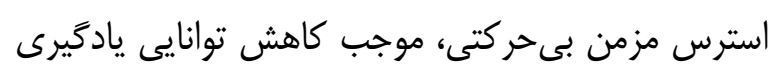

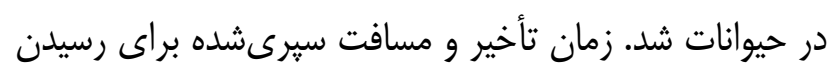

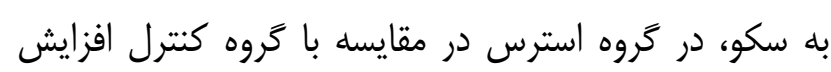

1.. mg/kg  د. m mg/kg

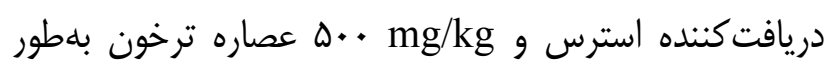
همزمان، تقسيم شدند. براى القاى استرس، حيوانات هر روز 9 ساعت (از ساعت فرنس

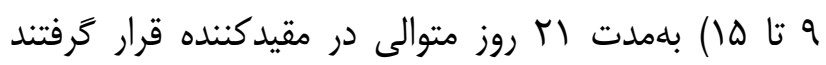

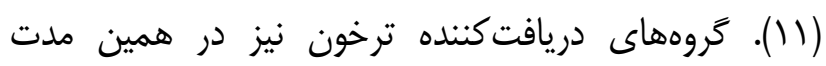

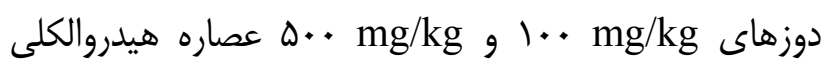
ترخون را بلهورت كَاواز دريافت نمودند (^). آزمون ماز آبى آماره

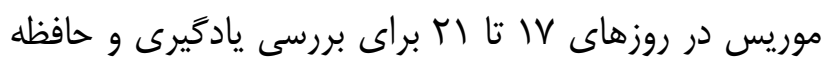
حيوانات به كار گرفته شد.


اطراف زنجان جمعآورى و توسط بخش كياهشناسى مركز





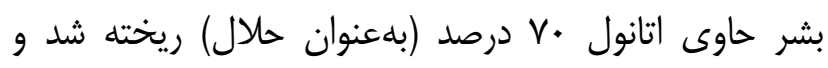




دماى •ه درجه سانتى


آب مقطر، دوزهاى مورد نظر عصاره تهيه شد. براى بررسى يادگيرى و حافظه فضايى حيوانات، از آزمون





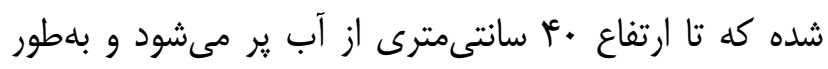

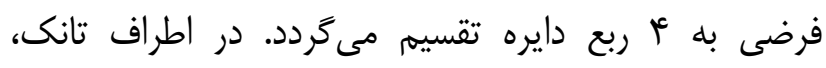

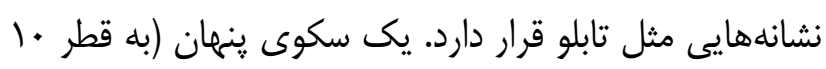

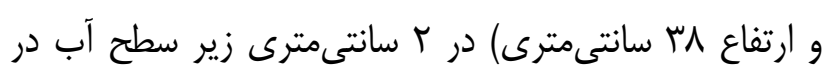
مركز يكى از ربع دايرههاى فرضى (در سمت شمال شرقى)

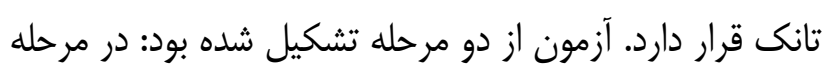

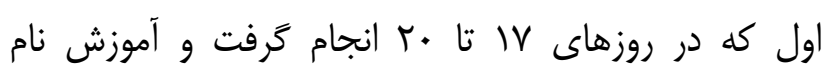




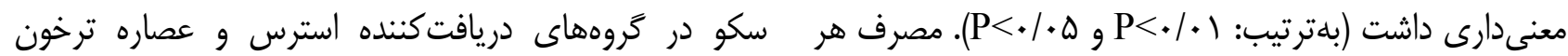
دو دوز عصاره ترخون موجب بهبود يادگيرى در حيوانات تحت بلهطور همزمان در مقايسه با حيوانات تحت استرس، كاهش

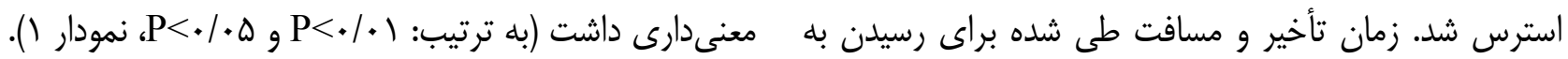

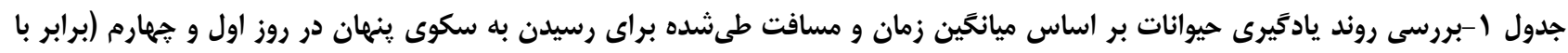

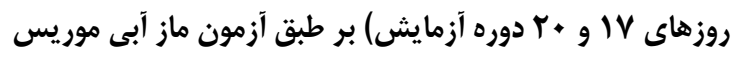

\begin{tabular}{|c|c|c|c|c|c|c|}
\hline \multicolumn{3}{|c|}{ زمان سيرىشده براى رسيدن به سكوى ينهان } & \multicolumn{3}{|c|}{ مسافت طىشده براى رسيدن به سكوى ينهان } & \multirow{3}{*}{$\begin{array}{c}\text { كرو } \\
(\mathrm{N}=1+)\end{array}$} \\
\hline \multirow{2}{*}{$\begin{array}{c}\text { آزمون - معىدارى } \\
\text { test } \\
\text { Test }\end{array}$} & \multicolumn{2}{|c|}{ ميانغين ذخطاى استاندارد } & \multirow{2}{*}{$\begin{array}{c}\text { آزمون - معنىدارى } \\
\text { test } \\
\text { Test }\end{array}$} & \multicolumn{2}{|c|}{ ميانغَين دخطاى استاندارد } & \\
\hline & روز F & روز I & & روز F & روز I & \\
\hline$<\cdot 1 \cdots 1$ & $\cdot / f^{c} V \pm 1 \cdot / \Delta$ & سع/א & $<\cdot 1+\cdots 1$ & $r / / m V \pm r V q / \Lambda$ & $\Delta q / q \pm 1 \cdot \Delta \wedge / 1$ & كنترل \\
\hline$<\bullet / \cdots 1$ & $\cdot / \Lambda T \pm \mid Y / q Y$ & $r / q r \pm V r / c r$ & $<\cdot / \cdot \bullet$ & $\mid \Delta / \Lambda H_{ \pm} \varepsilon \Delta M / \mathcal{F}$ & $\Delta F / r q \pm \| 1 / r q / r$ & 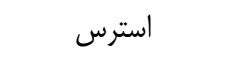 \\
\hline$<\bullet / \cdots 1$ & $\cdot / \Delta \xi \pm q / q \varepsilon$ & $r / \mathbb{R} V \pm V \cdot / r r$ & $<\cdot / \cdot 1$ & $1 \cdot / q \vee \pm r q V / c$ & 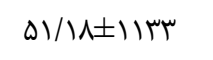 & 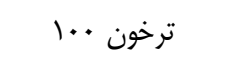 \\
\hline$<\bullet / \cdots 1$ & $\cdot \mid \Delta \Lambda \pm 1 \cdot / \cdot \vee$ & $T / Y T \pm \& \wedge / G Y$ & $<\cdot / \cdot \bullet$ & $1 \varepsilon / r \Delta \pm r V \Delta$ & $q r / q \cdot \pm|r| r / q$ & 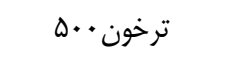 \\
\hline$<\bullet / \cdots 1$ & $\cdot / 9 \Lambda \pm 11 / \cdot r$ & $r / T H \pm \varnothing \Delta / 9 V$ & $<\cdot / \cdot \bullet$ & $I V / \cdot r \pm r V q / q$ & $\Delta \varepsilon / \varphi \mid \pm \| I I T / r$ & استرس-ترخون +. \\
\hline$<\cdot 1 \cdots 1$ & $\cdot / q \mu \pm 1 \cdot / \varepsilon$. & $r / r r \pm \Phi V / D$. & $<\cdot 1 \cdot+1$ & $11 / V V \pm r v g$ & $\Delta r / / V \pm \| F T / V$ & استرس -ترخون . هـ \\
\hline
\end{tabular}

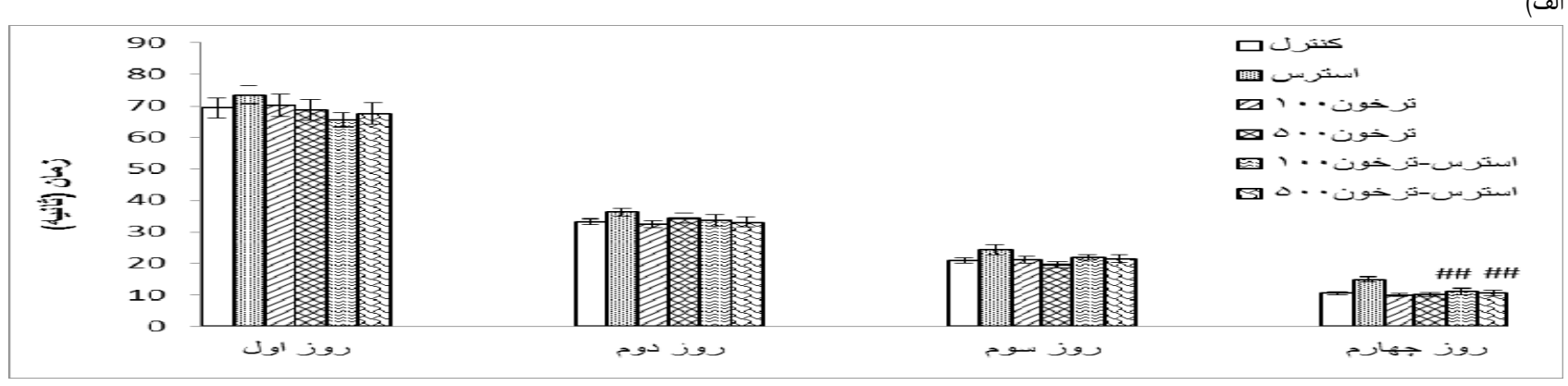

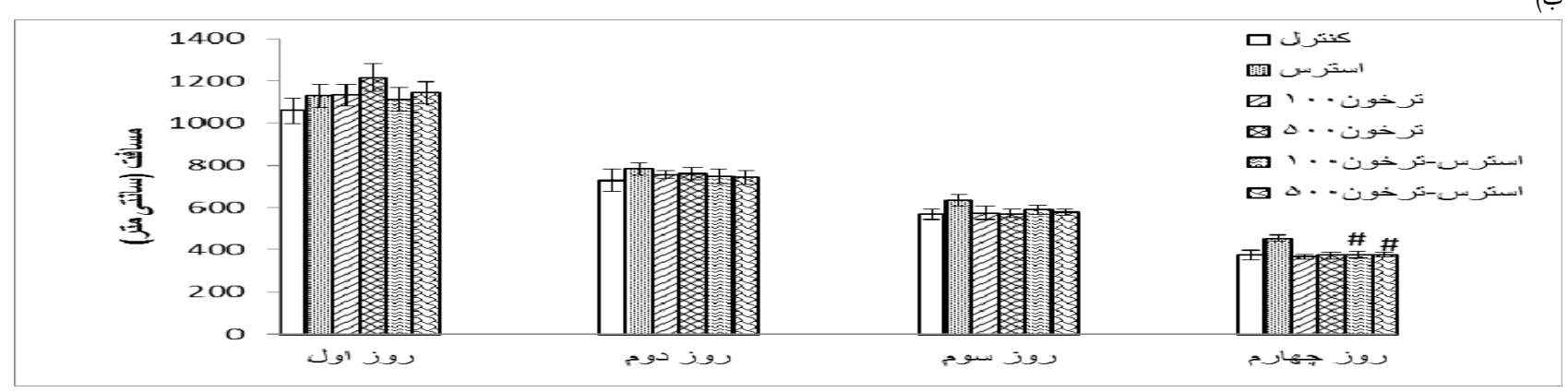

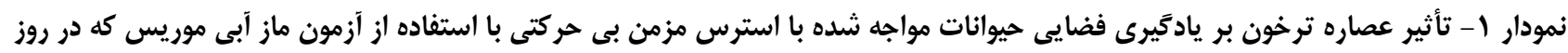

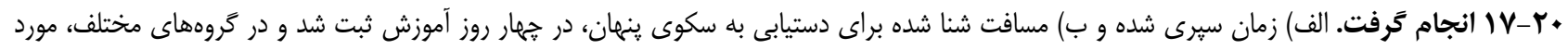

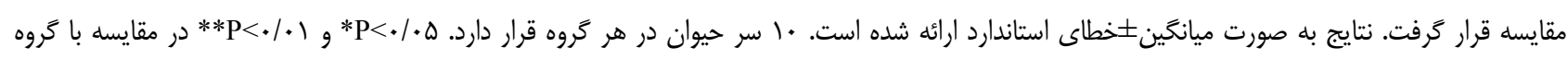

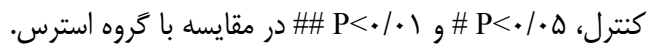



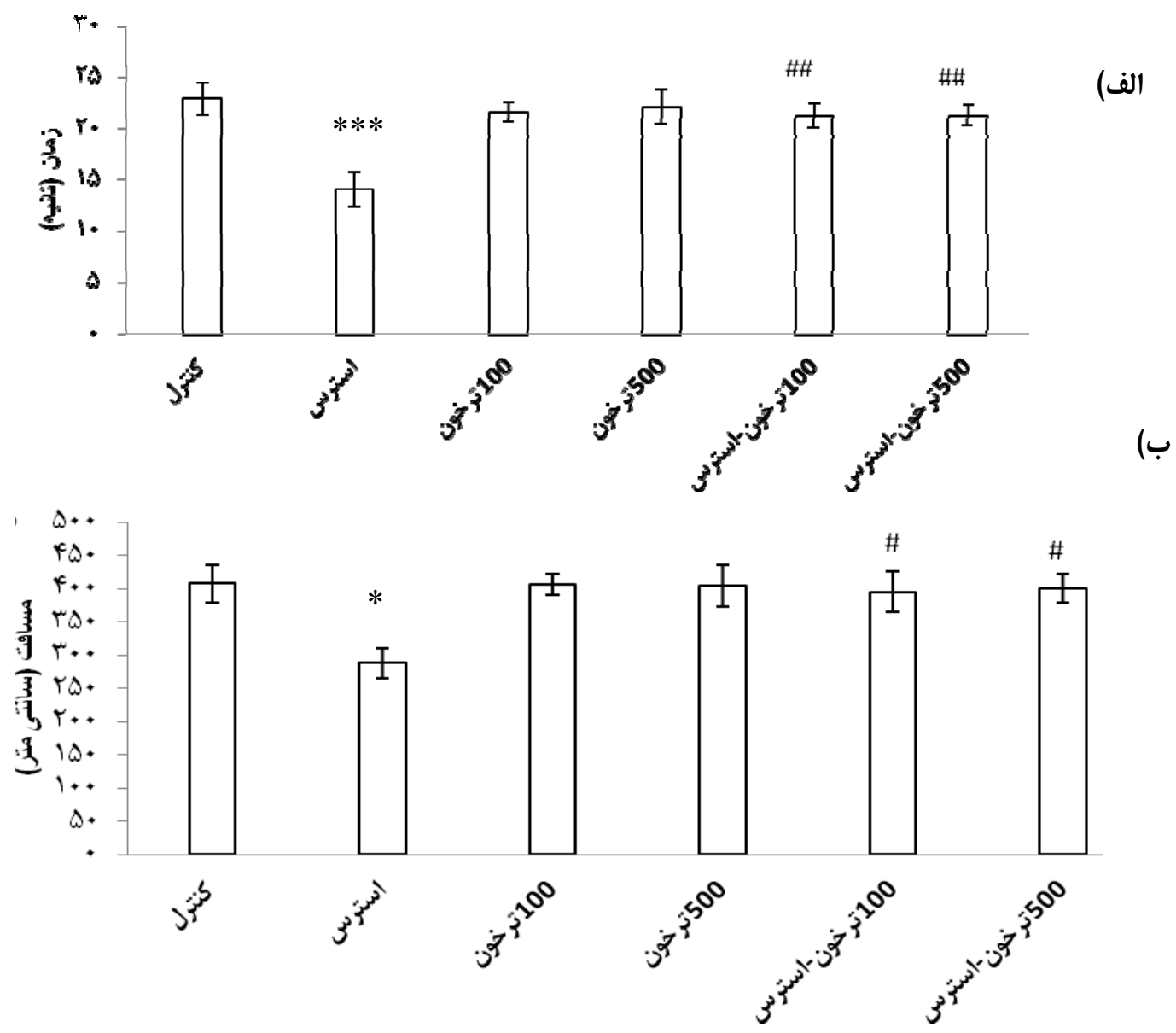

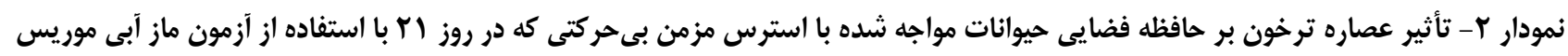

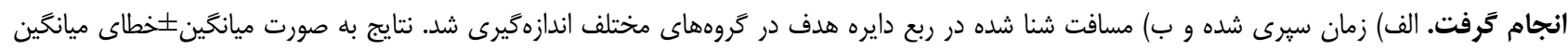

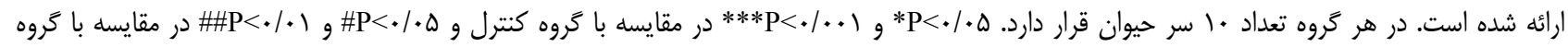

استرس.

\section{بحث}

نتايج حاصل از مطالعه حاضر نشان داد كه بى حركتى

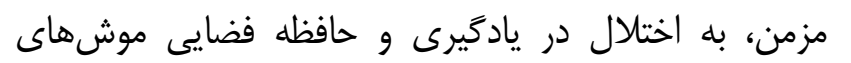

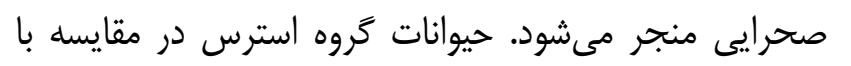

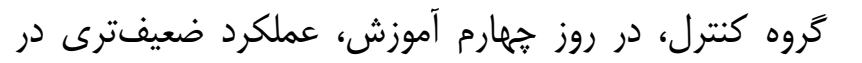

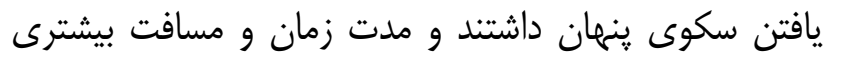

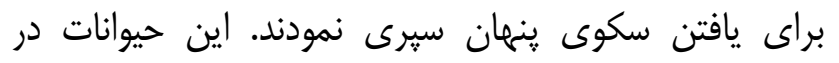

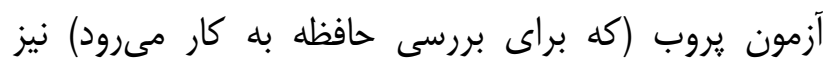

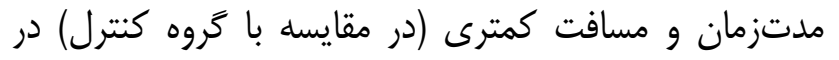

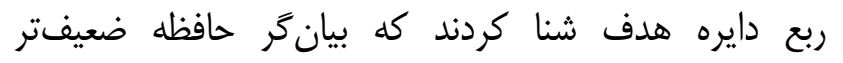

براى بررسى حافظه فضايى، آزمون يروب انجام شد.

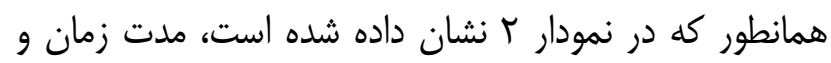

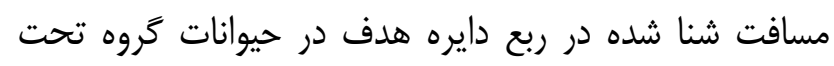

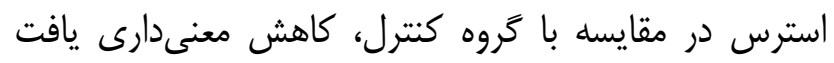

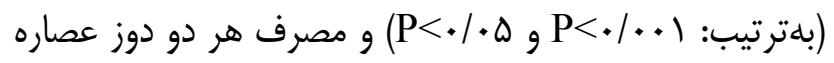
ترخون موجب افزايش زمان و مسافت سيرى شده در ربع اهن

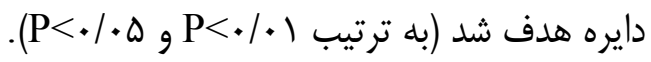


فلاونوئيدها، اسيدهاى فنلى، كومارين، كافئيك اسيد، تر كيبات

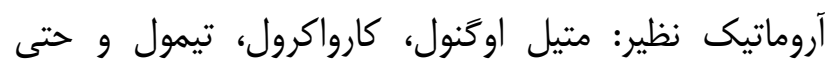

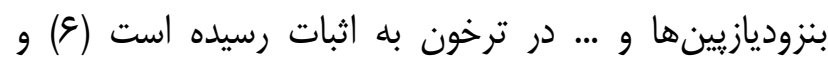
شواهد فراوانى مبنى بر آن كه تركيبات مذكور اثر مثبتى بر دران

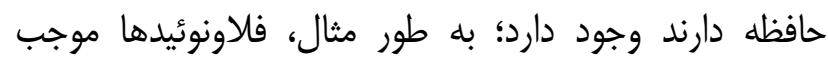

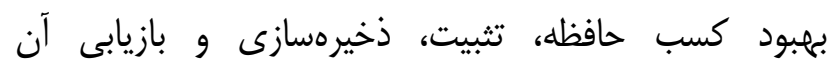

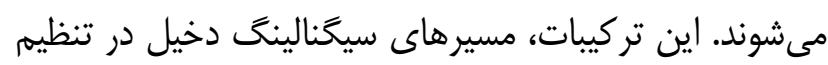

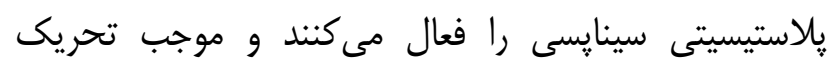

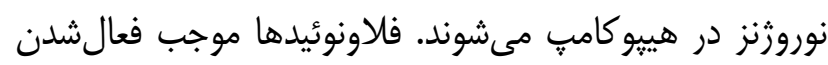
مسيرهاى سيخنالينَ MAPK' (نوعى فاكتور رونويسى كه موجب افزايش بيان تعدادى از سيكنينا

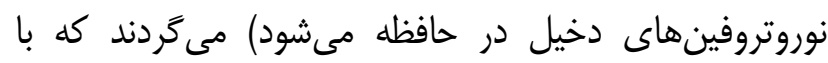

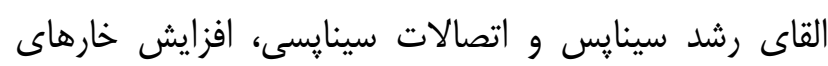

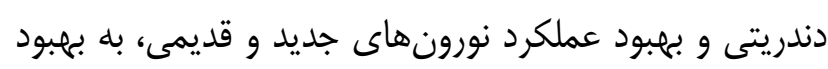

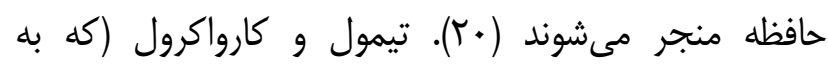

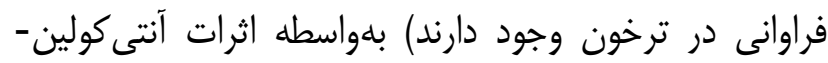

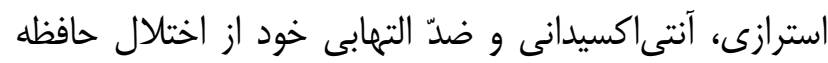
القا شده توسط تزريق درونهييو كاميى بتاآميلوئيد در رتها آنها

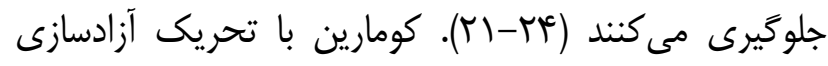

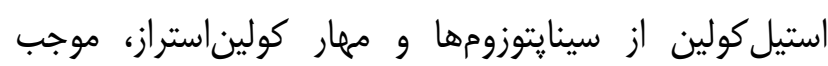

بهبود نقصان حافظه مىشود (Tه).

\section{نتيجل كيرى}

در مجموع نتيجهَيرى مى شود كه ترخون در هر دو دوز

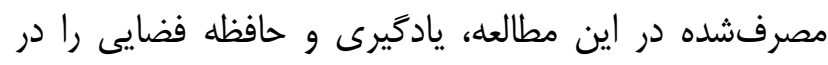
موشهاى تحت استرس بهبود مى خشد و ممكن است گزينه

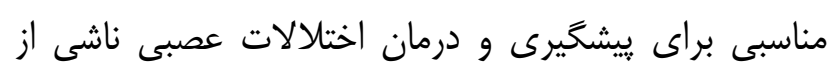

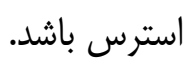

\footnotetext{
${ }^{1}$ Mitogen-activated protein kinase

${ }^{2}$ Extracellular signal-regulated kinase 1/2
}

آنهاست. اين نتايج با يافتههاى مطالعهاى در زمينه تأثير بى حركتى مزمن بر حافظه فضايى همسو است (سار)؛ هر جند

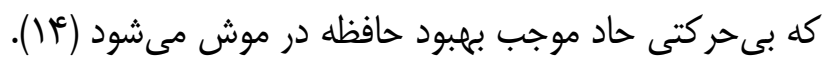

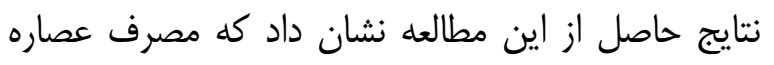

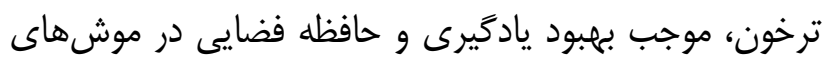
صحرايى تحت استرس مزمن بى حركتى شد. ثابت شده است

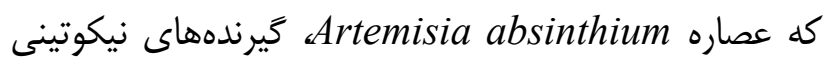
و موسكارينى استيل كولين را در نورونهاى كورتكس تحريك

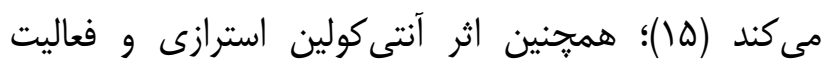

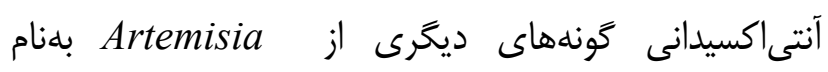
A. herba-alba Artemisia absinthium A. fragrans تشكيل و حفظ حافظه از اهميت فراوانى برخوردار است (ع) (1). استرس بى حركتى مزمن بلمدات الr روز، فعاليت كولين استراز

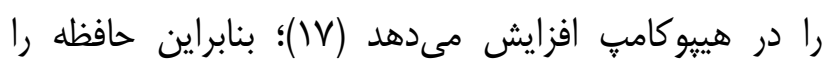

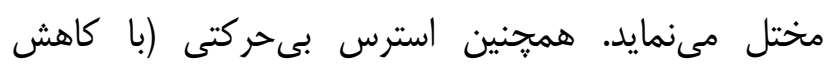
فعاليت آنزيمهاى آنتىاكسيدانى و افزايش توليد رحتين راديكال هاى آزاد) موجب تضعيف سيستم آنتىاكسيدانى در هيبيوكاني

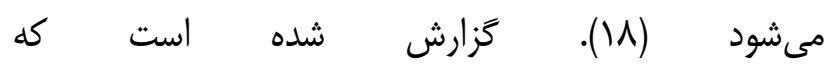
Artemisia dracunculus

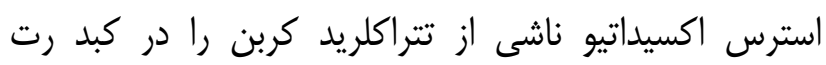

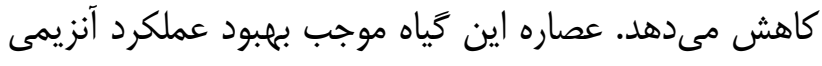
در كبد رتهاى مواجلشده با تتراكلريدكربن شده و با كاهش ماه

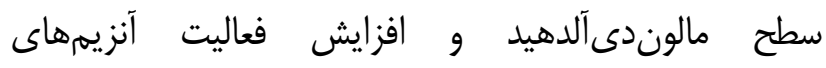
آنتىاكسيدانى، كبد را در برابر تتراكلريد كربن محافظت

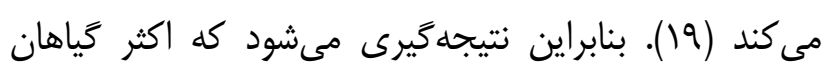
كونه Artemisia احتمالاً با تقويت سيستهم آنتى اكسيدانى در

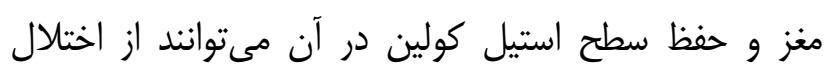

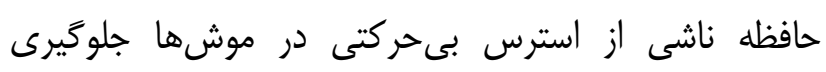
نمايند. اثر محافظتى Artemisia dracunculus بر حافظه مىتوان به تركيبات موجود در اين زياه نسبت داد. حضور 


$$
\begin{aligned}
& \text { مىشود؛ همجنين از خانم ليلا رجاييان براى كمى در انجام }
\end{aligned}
$$

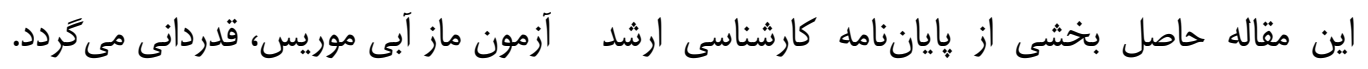

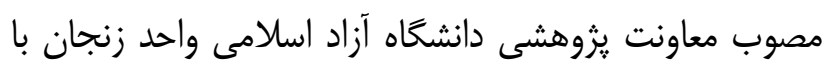

$$
\begin{aligned}
& \text { تضاد منافع }
\end{aligned}
$$

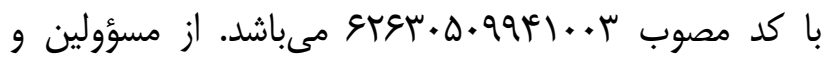

$$
\begin{aligned}
& \text { نويسندكان مقاله اعلام مى دارند كه هيج كَونه تضاد } \\
& \text { كارشناسان محترم مركز تحقيقات بيولوزى واحد زنجان بـ مدابه }
\end{aligned}
$$

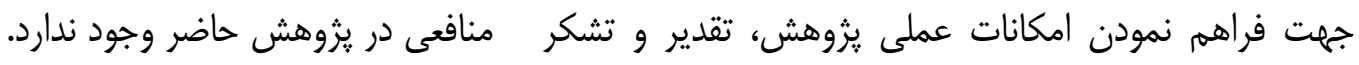

1- McEwen BS. Physiology and neurobiology of stress and adaptation: central role of the brain. Physiol Rev. 2007; 87(3): 873-904. DOI: 10.1152 /physrev.00041.2006

2- Sies H. Oxidative stress: a concept in redox biology and medicine. Redox Biol. 2015. 4: 180-3. doi: 10.1016/j.redox.2015.01.002.

3- Cheignon C, Tomas M, Bonnefont-Rousselot D, Faller P, Hureau C, Collin F. Oxidative stress and the amyloid beta peptide in Alzheimer's disease. Redox Biol. 2018; 14: 450-64. doi: 10.1016/j.redox.2017.10.014.

4- McEwen BS, Bowles NP, Gray JD, Hill MN, Hunter RG, Karatsoreos IN, et al. Mechanisms of stress in the brain. Nat Neurosci. 2015; 18(10): 1353-63. doi: 10.1038/nn.4086

5- Uttara B, Singh AV, Zamboni P, Mahajan RT. Oxidative stress and neurodegenerative diseases: a review of upstream and downstream antioxidant therapeutic options. Curr Neuropharmacol. 2009; 7(1): 65-74. doi: $10.2174 / 157015909787602823$

6- Obolskiy D, Pischel I, Feistel B, Glotov N, Heinrich M. Artemisia dracunculus L.(tarragon): a critical review of its traditional use, chemical composition, pharmacology, and safety. J Agr Food Chem. 2011; 59(21): 11367-84. doi: $10.1021 / \mathrm{j} f 202277 \mathrm{w}$.

7- Aglarova AM. Comparative Analysis of Secondary Metabolites of Artemisia dracunculus L., Russian and French cultivars [Dissertation]. Mahachkala; 2006.

8- Ribnicky DM, Kuhn P, Poulev A, Logendra S, Zuberi A, Cefalu WT, et al. Improved absorption and bioactivity of active compounds from an anti-diabetic extract of Artemisia dracunculus L. Int J Pharm. 2009; 370(1-2): 87-92. doi: 10.1016/j.ijpharm.2008.11.012.

9- Maham M, Moslemzadeh H, Jalilzadeh-Amin G. Antinociceptive effect of the essential oil of tarragon (Artemisia dracunculus). Pharm Biol. 2014; 52(2): 208-12. doi: 10.3109/13880209.2013.824007.

10- Orhan IE, Belhattab R, Şenol FS, Gülpinar AR, Hoşbaş S, Kartal M. Profiling of cholinesterase inhibitory and antioxidant activities of Artemisia absinthium, A. herba-alba, A. fragrans, Marrubium vulgare, M. astranicum, Origanum vulgare subsp. glandulossum and essential oil analysis of two Artemisia species. Ind Crops Prod. 2010; 32(3): 566-71. doi: 10.1016/j.indcrop.2010.07.005

11- MacDowell KS, Caso JR, Martín-Hernández D, Madrigal JL, Leza JC, García-Bueno B. Paliperidone prevents brain Toll-like receptor 4 pathway activation and neuroinflammation in rat models of acute and chronic restraint stress. Int $\mathrm{J}$ Neuropsychopharmacol. 2014 Oct 31;18(3). pii: pyu070. doi: 10.1093/ijnp/pyu070.

12- Asle-Rousta M, Oryan S, Ahmadiani A, Rahnema M. Activation of sphingosine 1-phosphate receptor-1 by SEW2871 improves cognitive function in Alzheimer's disease model rats. EXCLI J. 2013; 12: 449-61.

13- Huang RR, Hu W, Yin YY, Wang YC, Li WP, Li WZ. Chronic restraint stress promotes learning and memory impairment due to enhanced neuronal endoplasmic reticulum stress in the frontal cortex and hippocampus in male mice. Int J Mol Med. 2015; 35(2): 553-9. doi: 10.3892/ijmm.2014.2026.

14- Luine V, Martinez C, Villegas M, Magariños AM, McEwen BS. Restraint stress reversibly enhances spatial memory performance. Physiol Behav. 1996; 59(1): 27-32. DOI: 10.1016/0031-9384(95)02016-0 
15- Wake G, Pickering A, Lewis R, Wilkins R, Perry E. CNS acetylcholine receptor activity in European medicinal plants traditionally used to improve failing memory. J Ethnopharmacol. 2000; 69(2): 105-14.

16- Yu J, Kwon H, Cho E, Kang RH, Youn K, Jun M, et al. The effects of pinoresinol on cholinergic dysfunctioninduced memory impairments and synaptic plasticity in mice. Food Chem Toxicol. 2019; 125: 376-82. doi: 10.1016/j.fct.2019.01.017.

17- Sunanda, Rao BS, Raju TR. Restraint stress-induced alterations in the levels of biogenic amines, amino acids, and AChE activity in the hippocampus. Neurochem Res. 2000; 25(12): 1547-52.

18- Fontella FU, Siqueira IR, Vasconcellos AP, Tabajara AS, Netto CA, Dalmaz C. Repeated restraint stress induces oxidative damage in rat hippocampus. Neurochem Res. 2005; 30(1): 105-11.

19- Zarezade V, Moludi J, Mostafazadeh M, Mohammadi M, Veisi A. Antioxidant and hepatoprotective effects of Artemisia dracunculus against CCl4-induced hepatotoxicity in rats. Avicenna J Phytomed. 2018; 8(1): 51-62.

20- Spencer JP. The impact of flavonoids on memory: physiological and molecular considerations. Chem Soc Revi. 2009; 38(4): 1152-61. doi: 10.1039/b800422f.

21- Jukic M, Politeo O, Maksimovic M, Milos M, Milos M. In vitro acetylcholinesterase inhibitory properties of thymol, carvacrol and their derivatives thymoquinone and thymohydroquinone. Phytother Res. 2007; $21(3)$ : $259-61$. DOI: $10.1002 /$ ptr.2063

22- Majlessi N, Choopani S, Kamalinejad M, Azizi Z. Thymol as a main constituent of zataria multiflora boiss: essential oil attenuates amyloid $\beta$-induced cognitive deficits in a rat model of Alzheimer's disease. Alzheimers Dement 2011; 7(4): S770. DOI: https://doi.org/10.1016/j.jalz.2011.05.2214

23- Azizi Z, Ebrahimi S, Saadatfar E, Kamalinejad M, Majlessi N. Cognitive-enhancing activity of thymol and carvacrol in two rat models of dementia. Behav pharmacol. 2012; 23(3): 241-9. doi: 10.1097/FBP.0b013e3283534301.

24- Deng W, Lu H, Teng J. Carvacrol attenuates diabetes-associated cognitive deficits in rats. J Mol Neurosci. 2013; 51(3): 813-9. doi: 10.1007/s12031-013-0069-6.

25- Kiani A, Jalili-baleh L, Abdollahi Z, Nadri H, Foroumadi A, Sadat Ebrahimi SE, Khoobi M. Cholinesterase Inhibition Activity and Docking Simulation Study of Coumarin Mannich Base Derivatives. J Sci I.R Iran. 2019; 30(1): 5-12. DOI: 10.22059/jsciences.2019.256053.1007247 